The following resources related to this article are available online at www.sciencemag.org (this information is current as of October 14, 2009 ):

Updated information and services, including high-resolution figures, can be found in the online version of this article at:

http://www.sciencemag.org/cgi/content/full/326/5949/67

Supporting Online Material can be found at:

http://www.sciencemag.org/cgi/content/full/326/5949/67/DC1

A list of selected additional articles on the Science Web sites related to this article can be found at:

http://www.sciencemag.org/cgi/content/full/326/5949/67\#related-content

This article cites 25 articles, 2 of which can be accessed for free:

http://www.sciencemag.org/cgi/content/full/326/5949/67\#otherarticles

This article has been cited by 2 articles hosted by HighWire Press; see:

http://www.sciencemag.org/cgi/content/full/326/5949/67\#otherarticles

This article appears in the following subject collections:

Anthropology

http://www.sciencemag.org/cgi/collection/anthro

Information about obtaining reprints of this article or about obtaining permission to reproduce this article in whole or in part can be found at:

http://www.sciencemag.org/about/permissions.dtl 


\title{
Macrovertebrate Paleontology and the Pliocene Habitat of Ardipithecus ramidus
}

\author{
Tim D. White, Stanley H. Ambrose, Gen Suwa, Denise F. Su, David DeGusta, Raymond L. Bernor, \\ Jean-Renaud Boisserie, Michel Brunet, Eric Delson, Stephen Frost, Nuria Garcia, Ioannis X. Giaourtsakis, \\ Yohannes Haile-Selassie, F. Clark Howell, Thomas Lehmann, Andossa Likius, Cesur Pehlevan, Haruo \\ Saegusa, Gina Semprebon, Mark Teaford, Elisabeth Vrba
}

$\mathrm{E}$ ver since Darwin, scholars have speculated about the role that environment may have played in human origins, evolution, and adaptation. Given that all living great apes live and feed in trees, it has been assumed that the last common ancestor we shared with these forms was also a forest dweller. In 1925, Raymond Dart described the first Australopithecus, a child's skull, at Taung, South Africa. Its occurrence among other fossils indicative of a grassland environment prompted speculation that the open grasslands of Africa were exploited by early hominids and were therefore somehow integrally involved with the origins of upright walking.

The Ardipithecus-bearing sediments at Aramis now provide fresh evidence that $A r$ ramidus lived in a predominantly woodland setting. This and corroborative evidence from fossil assemblages of avian and small mammals imply that a grassland environment was not a major force driving evolution of the earliest hominids. A diverse assemblage of large mammals ( $>5 \mathrm{~kg}$ body weight) collected alongside Ardipithecus provides further support for this conclusion. Carbon isotopes from tooth enamel yield dietary information because different isotope signatures reflect different photosynthetic pathways of plants consumed during enamel development. Therefore, animals that feed on tropical open-environment grasses (or on grass-eating animals) have different isotopic compositions from those feeding on browse, seeds, or fruit from shrubs or trees. Moreover, oxygen isotopes help deduce relative humidity and evaporation in the environment.

The larger-mammal assemblage associated with Ardipithecus was systematically collected across a $\sim 9 \mathrm{~km}$ transect of eroding sediments sandwiched between two volcanic horizons each dated to 4.4 million years ago. It consists of $\sim 4000$ cataloged specimens assigned to $\sim 40$ species in 34 genera of 16 families.

There are only three primates in this assemblage, and the rarest is Ardipithecus, represented by 110 specimens (a minimum of 36 individuals). Conversely, colobine monkeys and a small baboon-like monkey

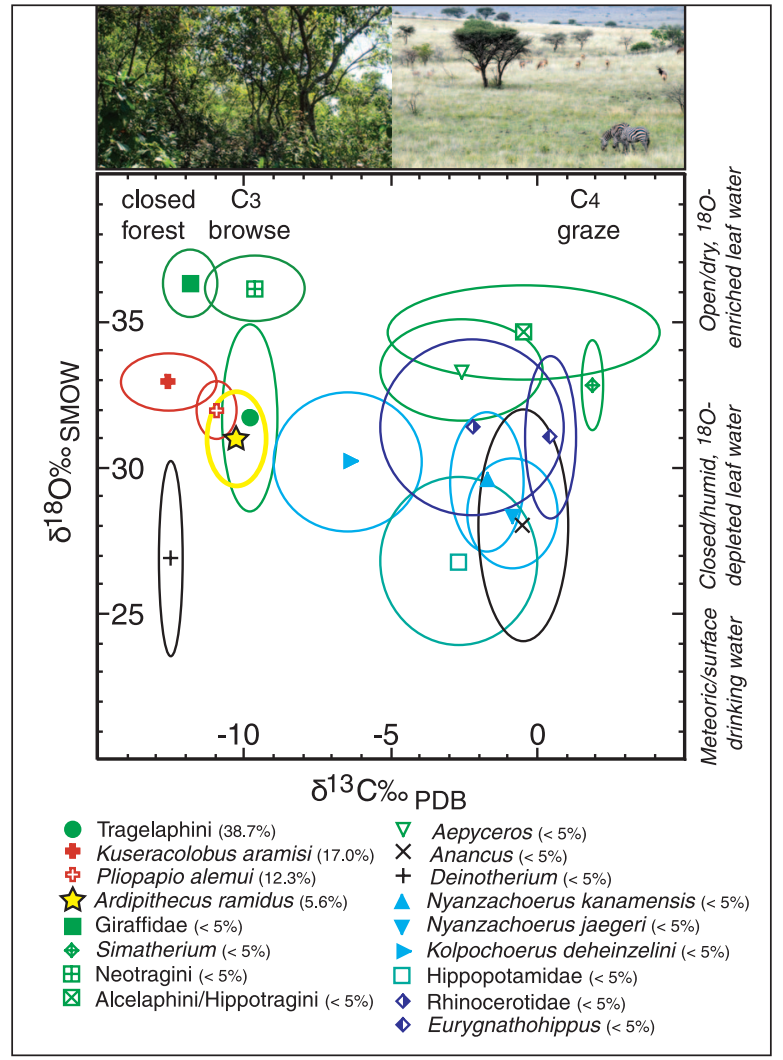

Carbon and oxygen isotope analyses of teeth from the Ar. ramidus localities. Species are listed in order of abundance, and isotopic data separate species by what they ate and their environment. (red crosses in figure) account for nearly a third of the entire large mammal collection. Leaf-eating colobines today exhibit strong preferences for arboreal habitats, and the carbon isotope compositions of the fossil teeth are consistent with dense to open forest arboreal feeding (see figure).

The other dominant large mammal associated with $A r$ ramidus is the spiral-horned antelope, Tragelaphus (the kudu, green circle). Today, these antelopes are browsers (eating mostly leaves), and they prefer bushy to wooded habitats. The dental morphology, wear, and enamel isotopic composition of the Aramis kudu species are all consistent with such placement. In contrast, grazing antelopes (which eat mostly grass) are rare in the Aramis assemblage.

The large-mammal assemblage shows a preponderance of browsers and fruit eaters. This evidence is consistent with indications from birds, small mammals, soil isotopes, plants, and invertebrate remains. The emergent picture of the Aramis landscape during Ar. ramidus times is one of a woodland setting with small forest patches. This woodland graded into nearby habitats that were more open and are devoid of fossils of Ardipithecus and other forest-to-woodlandcommunity mammals. Finally, the carbon isotopic composition of Ar. ramidus teeth is similar to that of the predominantly arboreal, small, baboon-like Pliopapio and the woodland browser Tragelaphus, indicating little dietary intake of grass or grass-eating animals. It is therefore unlikely that Ar. ramidus was feeding much in open grasslands.

These data suggest that the anatomy and behavior of early hominids did not evolve in response to open savanna or mosaic settings. Rather, hominids appear to have originated and persisted within more closed, wooded habitats until the emergence of more ecologically aggressive Australopithecus.

When citing, please refer to the full paper, available at DOI 10.1126/science.1175822. 


\section{Macrovertebrate Paleontology and the Pliocene Habitat of Ardipithecus ramidus}

Tim D. White, ${ }^{1 *}$ Stanley H. Ambrose, ${ }^{2}$ Gen Suwa, ${ }^{3}$ Denise F. Su, ${ }^{4}$ David DeGusta, ${ }^{5}$ Raymond L. Bernor, ${ }^{6,7}$ Jean-Renaud Boisserie, ${ }^{8,9}$ Michel Brunet, ${ }^{10}$ Eric Delson, ${ }^{11,12}$ Stephen Frost, ${ }^{13}$ Nuria Garcia, ${ }^{14}$ Ioannis X. Giaourtsakis, ${ }^{15}$ Yohannes Haile-Selassie, ${ }^{16}$ F. Clark Howell, ${ }^{17} \dagger$ Thomas Lehmann, ${ }^{18}$ Andossa Likius, ${ }^{19}$ Cesur Pehlevan, ${ }^{20}$ Haruo Saegusa, ${ }^{21}$ Gina Semprebon, ${ }^{22}$ Mark Teaford, ${ }^{23}$ Elisabeth Vrba ${ }^{24}$

A diverse assemblage of large mammals is spatially and stratigraphically associated with Ardipithecus ramidus at Aramis. The most common species are tragelaphine antelope and colobine monkeys. Analyses of their postcranial remains situate them in a closed habitat. Assessment of dental mesowear, microwear, and stable isotopes from these and a wider range of abundant associated larger mammals indicates that the local habitat at Aramis was predominantly woodland. The Ar. ramidus enamel isotope values indicate a minimal $C_{4}$ vegetation component in its diet (plants using the $C_{4}$ photosynthetic pathway), which is consistent with predominantly forest/woodland feeding. Although the Early Pliocene Afar included a range of environments, and the local environment at Aramis and its vicinity ranged from forests to wooded grasslands, the integration of available physical and biological evidence establishes Ar. ramidus as a denizen of the closed habitats along this continuum.

$\mathrm{C}$ ircumscribing the ecological habitat of the earliest hominids is crucial for understanding their origins, evolution, and adaptations. Evidence integrated from a variety of independent geological and paleontological sources (1-3) help to place Ardipithecus ramidus in its regional and local Pliocene environmental settings. Here, we assess fossils of the larger vertebrates (mammalian families in which most species exceed $5 \mathrm{~kg}$ adult body weight) to reveal characteristics of their diets, water use, and habitat preferences.

At Aramis 4.4 Ma (million years ago), predominantly terrestrial plants, invertebrates, and vertebrates were buried relatively rapidly on a low-relief aggrading floodplain, away from perennially moving water capable of displacing most remains $(2,3)$. Collection bias was avoided by a systematic $100 \%$ collection strategy (1). Therefore, the large mammal assemblage spatially associated with Ardipithecus in the Lower Aramis Member allows for relatively robust and precise environmental inference compared with many other hominid-bearing occurrences

The assemblage was carnivore-ravaged and is consequently dominated by bone and dental fragments (3). It represents an attritionally derived fauna collected between two widespread marker tuffs that are today exposed along an extended erosional arc $(2,3)$. The larger mammal fossil assemblage (4) comprises 3837 individually cataloged specimens assigned to 42 species (6 of them newly discovered), in 34 genera of 16 families $(1,5)$, across a wide body size range (Fig. 1A). Many of the sampled taxa provide evidence for the evolution of African vertebrates.
We consider ecological habitat to mean the biological and physical setting normally and regularly inhabited by a particular species. Our floral definitions follow the United Nations Educational, Scientific, and Cultural Organization (UNESCO) classification of African vegetation (6). Forests have continuous stands of trees with overlapping crowns, forming a closed, often multistory canopy 10 to $50 \mathrm{~m}$ high; the sparse ground layer usually lacks grasses. Forests grade into closed woodlands, which have less continuous canopies and poorly developed grass layers. Woodlands have trees with canopy heights of 8 to $20 \mathrm{~m}$; their crowns cover at least $40 \%$ of the land surface but do not overlap extensively. Woodland ground layer always includes heliophilous (sun-loving, $\mathrm{C}_{4}$ ) grasses, herbs/forbs, and incomplete small tree and shrub understories. Scrub woodland has a canopy height less than $8 \mathrm{~m}$, intermediate between woodland and bushland. As proportions of bushes, shrubs, and grasses increase, woodlands grade into bushland/thickets or wooded grasslands

Reconstructing the Aramis biotope. Reconstructing an ancient environment based on vertebrate macrofossils is often imprecise (7). Even assemblages from a single stratigraphic interval may sample thousands of years and thus represent artificial amalgamations of different biotopes shifting on the landscape through time. Even in a geologically isochronous assemblage, animals from different habitats may be mixed by moving water or by a moving lake or river margin. Ecological fidelity can be further biased through unsystematic paleontological recovery, for example, when only more complete, identifiable, and/or rare specimens are collected.
Consequently, most early hominid-bearing open-air fossil assemblages conflate multiple biotopes (7). Under such circumstances, it is not surprising that many Pliocene hominid habitats have been referred to as a "mosaic" or "a changing mosaic of habitats" (8). Such characterizations risk confusing noise for signal and local for regional environment, particularly for collection-biased assemblages lacking temporal and spatial resolution.

Initial assessment of the fauna associated with Ar. ramidus indicated "a closed, wooded" environment (9), an inference subsequently misquoted as "forest" (10). This interpretation was criticized on the basis that colobine monkeys and tragelaphine bovids might be unreliable indicators $(11,12)$.

Taxonomic abundance. Several aspects of Lower Aramis Member larger mammal assemblage abundance data constitute strong indicators of ancient biofacies and biotope (13). The locality-specific subassemblages are remarkably

${ }^{1}$ Human Evolution Research Center and Department of Integrative Biology, 3101 Valley Life Sciences Building, University of California, Berkeley, CA 94720, USA. 'Department of Anthropology, University of Illinois, 607 South Matthews Avenue, Urbana, IL 61801, USA. ${ }^{3}$ The University Museum, University of Tokyo, Hongo, Bunkyo-ku, Tokyo 113-0033, Japan. ${ }^{4}$ Department of Anthropology, Bryn Mawr College, Bryn Mawr, PA 19010-2889, USA. ${ }^{5}$ Department of Anthropology, Stanford University, Stanford, CA 94305-2034. ${ }^{6}$ National Science Foundation, Sedimentary Geology and Paleobiology Program, Arlington, VA 22230, USA. ${ }^{7}$ College of Medicine, Department of Anatomy, Laboratory of Evolutionary Biology, Howard University, 520 W Street, Washington, DC 20059, USA. ${ }^{8}$ Paléobiodiversite et Paléoenvironnements, UMR CNRS 5143, USM 0203, Muséum national d'histoire naturelle, 8 rue Buffon, CP 38, 75231 Paris cedex 05 , France. ${ }^{9}$ Institut de paléoprimatologie et paléontologie humaine, évolution et paléoenvironnements, UMR CNRS 6046, Université de Poitiers, 40 avenue du Recteur-Pineau 86022 Poitiers cedex, France. ${ }^{10}$ Collège de France, Chaire de Paléontologie humaine, 3 Rue d'Ulm, F-75231 Paris cedex 05, France. ${ }^{11}$ Department of Anthropology, Lehman College, City University of New York, Bronx, NY 10468, USA. ${ }^{12}$ Department of Vertebrate Paleontology, American Museum of Natural History, New York, NY 10024, USA. ${ }^{13}$ Department of Anthropology, University of Oregon, Eugene, OR, 974031218, USA. ${ }^{14}$ Departamento Paleontología, Universidad Complutense de Madrid y Centro de Evolución y Comportamiento Humanos, ISCIII, C/ Sinesio Delgado 4, Pabellón 14, 28029 Madrid, Spain. ${ }^{15}$ Ludwig-Maximilians-University of Munich, Department of Geo- and Environmental Sciences, Section of Paleontology, Richard-Wagner-Strasse 10, D-80333 Munich, Germany. ${ }^{16}$ Department of Physical Anthropology, Cleveland Museum of Natural History, 1 Wade Oval Drive, Cleveland, $\mathrm{OH}$ 44106, USA. ${ }^{17}$ Human Evolution Research Center and Department of Anthropology, 3101 Valley Life Sciences Building, University of California, Berkeley, CA 94720, USA. ${ }^{18}$ Senckenberg Forschungsinstitut, Senckenberganlage 25, D-60325 Frankfurt am Main, Germany. ${ }^{19}$ Département de Paléontologie, Université de N'Djamena, BP 1117 N'Djamena, Chad. ${ }^{20}$ University of Yuzuncu Yil, Department of Anthropology, Faculty of Science and Letters, Zeve Yerlesimi 65080 Van, Turkey. ${ }^{21}$ Institute of Natural and Environmental Sciences, University of Hyogo, Yayoigaoka, Sanda 669-1546, Japan. ${ }^{22}$ Science and Mathematics, Bay Path College, 588 Longmeadow Street, Longmeadow, MA 01106, USA. ${ }^{23}$ Center for Functional Anatomy and Evolution, Johns Hopkins University School of Medicine, 1830 East Monument Street, Room 303, Baltimore, MD 21205, USA. ${ }^{24}$ Department of Geology and Geophysics, Yale University, New Haven, CT 06520, USA.

*To whom correspondence should be addressed. E-mail: timwhite@berkeley.edu

†Deceased 
consistent in their taphonomy and taxonomy across the $\sim 7 \mathrm{~km}$ distance from the easternmost (SAG-VP-7) to westernmost (KUS-VP-2) $A r$. ramidus localities (3).

Contemporaneous localities between the two tuffs farther south of the modern Sagantole drainage (SAG-VP-1 and -3, at the southeastern paleotransect pole) are relatively impoverished. They lack this diverse and abundant mammal assemblage and contain no tragelaphines, no monkeys, no fossil wood or seeds, no birds, no micromammals, and no Ardipithecus (table S1). Complementary structural, taphonomic, and isotopic data from localities on this pole of the paleotransect suggest a more open landscape that supported more crocodilians, turtles, and hippopotamids, presumably associated with water-marginal settings more axial in the drainage basin $(2,3)$.
Relative and absolute abundance measures for the large mammals in our collections from the Ardipithecus-bearing Lower Aramis Member localities were assessed by the number of identified specimens (NISP) $(n=1930)$ and the minimum number of individuals (MNI) based on teeth $(n=330)$. Proboscideans, giraffids, and hippopotamids are rare (Fig. 1, B and C). The rhinos Ceratotherium efficax and Diceros are represented by few specimens (NISP 6 and 1, MNI 4 and 1 , respectively). Unlike most other waterside Plio-Pleistocene assemblages, rhinos are more abundant than hippos at Aramis. The dental mesowear pattern and occlusal morphology of Pliocene Ceratotherium efficax suggest that it was predominantly a grazer but ate less abrasive forage with respect to its highly specialized Pleistocene and extant descendant Ceratotherium simum. The morphological and functional properties of the recovered Diceros sp. molars are similar to those of the extant browsing Diceros bicornis.

Equids are rare. One, Eurygnathohippus sp. nov., is distinguished by its distal limb, which is adapted to open-country running. Its elongatenarrow snout with parabolic symphysis suggests adaptation to selective feeding. The teeth of this equid bear a low-blunt cusp morphology reflecting habitual grazing. Large carnivores and aardvarks are rare, in keeping with their trophic level (as in most other eastern African PlioPleistocene assemblages).

Ardipithecus ramidus is represented at Aramis and environs by $>110$ cataloged specimens representing a minimum number of 36 individuals [14 by upper second molar $\left(\mathrm{M}^{2}\right)$ count] in the Lower Aramis Member. These numbers are rel-
Fig. 1. Aramis large mammals. (A) Size range illustrated by astragali. The Lower Aramis Member contains a wide range of mammalian taxa, illustrated by this image. Top left, Rhinocerotidae; middle left, Ardipithecus ramidus (ARA-VP-6/500); lower left, small bovid. Included are other artiodactyls, carnivores, and rodents. (B) Relative abundance of larger mammal taxa at Aramis based on dental MNI. (C) Dental NISP based on dental individuals whose tooth crowns are more than half complete. The NISP value reflects all collected specimens identified to the taxon and excludes bulk specimens (tooth crowns less than half complete). Associated dental specimens are counted as one. The MNI values use permanent molars segregated into upper and lower first, second, and third molars, respectively. Numbers for each taxon vary between NISP and MNI, but the relative proportions hold similar. Tragelaphine bovids and cercopithecid monkeys dominate, accounting for more than half of the assemblage, however counted.

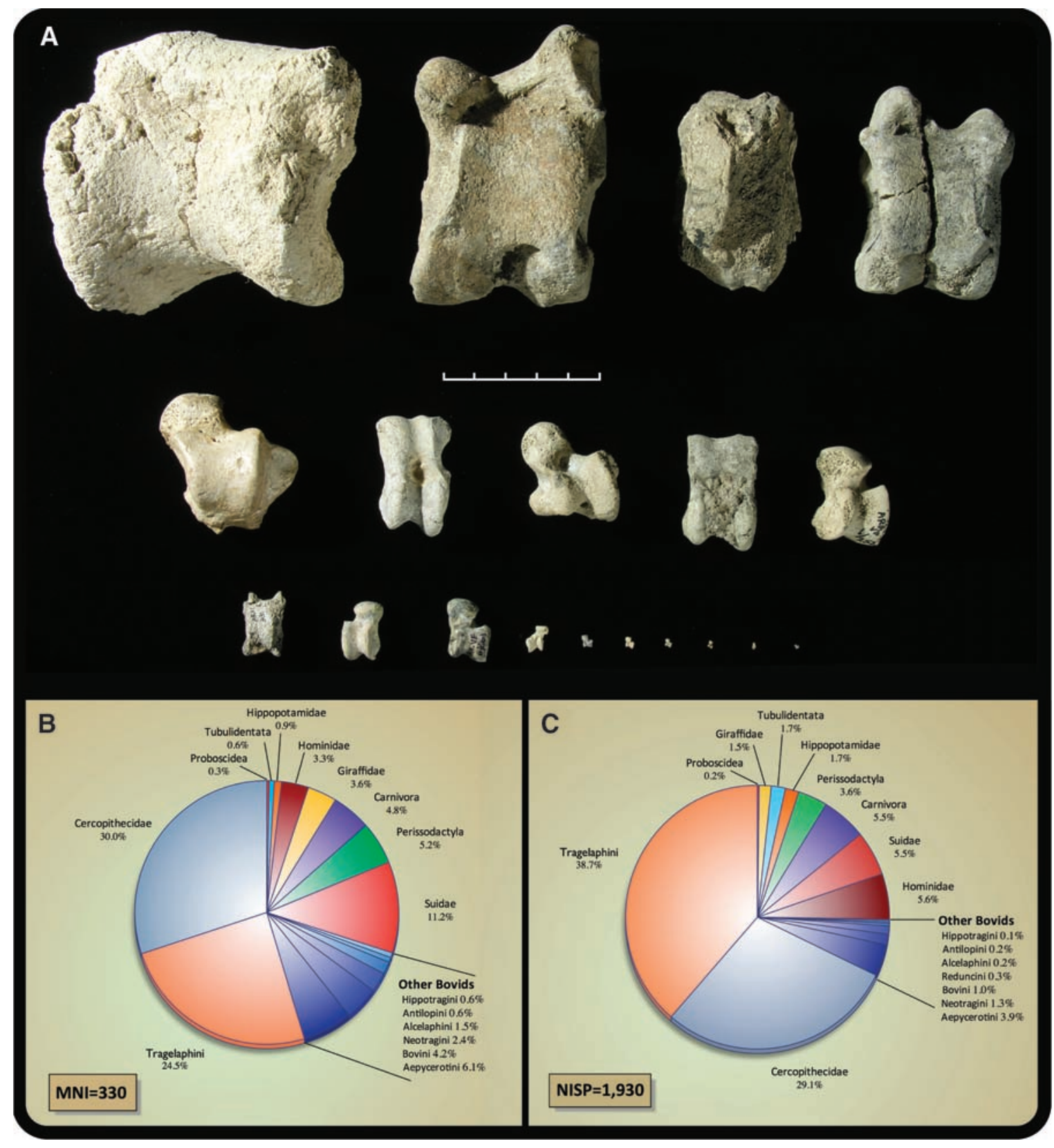


atively low compared with many of the other macrovertebrate fossil species we collected. This rarity is consistent with that observed for hominids in other well-known vertebrate assemblages (7). Kuseracolobus aramisi and Pliopapio alemui are ubiquitous in the assemblage, accounting for $30 \%$ of both the larger mammal NISP and MNI. The colobine is numerically dominant within nearly all of the localities, and overall by a ratio of 1.4 to Pliopapio (colobinae NISP:cercopithecinae NISP). It is slightly larger (12 kg female, $18 \mathrm{~kg}$ male) than this papionin $(8.5 \mathrm{~kg}, 12 \mathrm{~kg}$ ) based on dental regressions (14). Extant colobines exhibit strong preferences for arboreal habitats; extinct African taxa range from fully arboreal to highly terrestrial (15).

Bovids and primates, particularly tragelaphines and cercopithecids, dominate the larger mammal

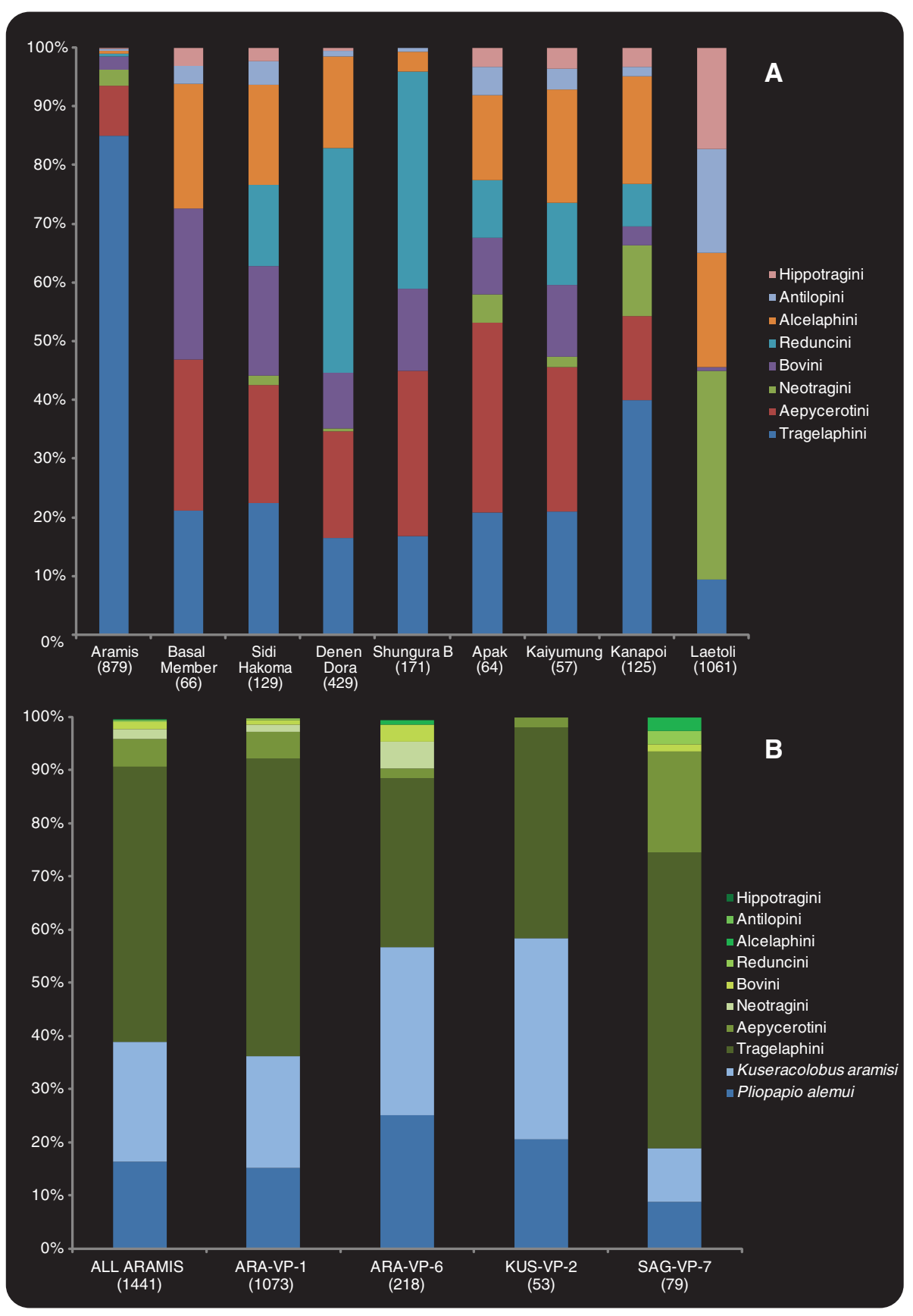

Fig. 2. Aramis taxonomic abundance. (A) Comparison between the relative abundance (dental) of bovid taxa at Aramis and other Plio-Pleistocene sites $(21,23,45)$. The bovid fauna at Aramis is markedly different due to the dominance of tragelaphines. All frequencies are based on NISP, except for Hadar, which is based on MNI. (B) Within-site comparison of the relative abundances of bovids and cerocopithecids. Among Lower Aramis Member localities, SAG-VP-7 has relatively lower abundances of cercopithecids and higher abundances of alcelaphines and reduncines, potentially indicative of ecotonal conditions at this easternmost locality of the Ardipithecus distribution. assemblage based on taxonomically diagnostic craniodental elements (Fig. 1). Together, these taxa account for more than half of the larger mammal specimens, whether counted by NISP or dental MNI. Both cercopithecid and bovid assemblages appear to be attritional and were ravaged heavily by carnivores after death (3).

Bovids help illuminate the local Aramis environment of the Ardipithecus-bearing localities. One useful index is the relative abundance of grazing versus browsing taxa, which can indicate the presence of open or closed conditions, respectively (16-19). The most ecologically sensitive of these taxa include grazing, open-habitat tribes such as Alcelaphini and Hippotragini versus the primarily browsing Tragelaphini or the riparian-associated Reduncini. Reduncine bovids commonly dominate in African Plio-Pleistocene faunal assemblages (Fig. 2), in keeping with fluviatile, swampy, or lake marginal depositional conditions.

Whether counted by NISP or dental MNI, Tragelaphus (whose modern congeners are associated with wooded habitats) (20) is the numerically dominant Aramis bovid, comprising $85 \%$ (NISP) of the bovid assemblage (Fig. 1), followed by Aepyceros (whose modern form favors grassy woodland to wooded grassland environments). In contrast, alcelaphine and reduncine bovids that are plentiful at other Plio-Pleistocene sites are rare at Aramis, accounting for a mere $1 \%$ (NISP) and 4\% (MNI) of all bovids. Aramis is unlike any other known African fossil assemblages in that Tragelaphus dominates the ungulates. (20-23) (Fig. 2).

Alcelaphines and reduncines were found at slightly higher frequencies at locality SAG-VP-7 at the eastern end of the Ardipithecus distribution (although tragelaphines and aepycerotines still dominate there). This subtle difference between SAG-VP-7 and other more westerly hominidbearing localities is also indicated by cercopithecid abundance. SAG-VP-7 has relatively fewer cercopithecids and more alcelaphine and reduncine bovids (Fig. 2), potentially signaling that this easternmost Ardipithecus locality was a transition zone between two biotopes.

Functional morphology. Taxon-based approaches to the inference of paleohabitats are usually restricted to using identifiable craniodental remains and assume that habitat preference persists through evolutionary time. Another approach is to evaluate the anatomy of fossils with respect to its implications for functional adaptations. These methods presume that mammals exhibit skeletal and dental adaptations for locomotion and feeding that correlate with their preferred environment (24). Samples of extant taxa are used to quantify the relations between skeletal/dental traits and environmental variables, with the results then applied to fossil forms (25).

Here, we evaluate the "ecomorphology" of the most common large mammals at Aramis, the bovids and cercopithecid monkeys. For the Aramis bovids, we evaluated the astragali and 
phalanges $(25,26)$ because other elements that can be revealing (metapodials and femora) were not preserved in sufficient numbers. We used a four-habitat grouping scheme (26) (SOM text $\mathrm{S} 1)$. Of the 11 available intact bovid astragali with statistically significant habitat predictions (accuracy $>95 \%$ ), 10 are classified as "forest" and one as "heavy cover." This is a clear signal, since these methods typically produce more varied habitat predictions when applied to fossil samples $(27,28)$. To lessen possible biases introduced by confining the analysis to specimens sufficiently complete for measurement, we also examined nonmetric traits of the phalanges and classified the entire astragali/phalangeal sample by morphotype (SOM text S1, tables S2 and S3, and fig. S1). These results independently support the conclusion from metric prediction that these animals inhabited a "forest" (in the analytical, not floral, sense).

As with bovids, cercopithecid postcranial features are routinely posited to indicate locomotion (29-31). However, systematic studies of large samples of extant taxa are generally lacking. We therefore consider most proposed correlations between cercopithecoid anatomy and locomotor mode to be of unknown reliability, pending additional study. Even so, the elbow is clearly a key joint for distinguishing between arboreal and terrestrial primate locomotion. Of 10 available Aramis cercopithecoid distal humeri, 9 are clearly consistent with "arboreal" substrate, whereas only one is consistent with "terrestrial" substrate based on current criteria. Of 9 proximal ulnae, all are arboreal. There was no clear evidence of terrestrial adaptation in 18 proximal radii. Hence, based on current criteria, there is clear evidence of arboreal locomotor adaptations, and a paucity of terrestrial indicators, in the overwhelming majority of the Aramis cercopithecoid postcranial sample (SOM text S2).

Dental wear. The morphology, occlusal wear, and stable isotope composition of dental remains also reveal the diet - and, indirectly, habitat preferences - of some Aramis mammals. Differences in mesowear can distinguish among extant browsers, grazers, and mixed feeders (32). The Aramis neotragines, Giraffa, and Tragelaphus cluster with extant browsers (Fig. 3 and table S3), whereas Aepyceros falls between extant mixed feeders and nonextreme grazers. Rare Aramis alcelaphines cluster with nonextreme grazers, whereas the rare bovine and equid fossils are closest to extant coarser grass grazers.

The high cusps and colobine-like morphology of Pliopapio alemui (tall molars with high relief and little basal flare) suggest that the two Aramis monkey taxa had similar diets. We sampled a mixed set of colobine and cercopithecine molars for a blind test of microwear. No significant differences were found between the two taxa. Microwear on the Aramis monkey molars is consistent with both frugivory and folivory but not hard object feeding. A diet of soft (but perhaps tough) foods would be typical of colobines, and the same may have been the case for the papionin (33).

Enamel isotopes. The carbon isotopic composition of a mammal's tooth enamel reflects the relative contributions of grass, trees, and shrubs to its diets. Oxygen isotopes can reveal the degree that a species lives in, or consumes, water from different sources (34). We sampled tooth enamel bioapatite from 177 specimens encompassing a wide range of mammalian taxa within the Ar. ramidus-bearing unit (Fig. 4, SOM text S3, and table S4). These were analyzed blind to taxon. Carbon isotopic ratios for grazers are high, whereas those for mixed feeders, browsers, and forest floor feeders decrease systematically (SOM text S4). Oxygen isotope vales are low for water-dependent species such as carnivores and hippos in wet riparian habitats and higher for water-independent browsers and open dryhabitat species.

In the Ardipithecus-bearing Lower Aramis Member assemblage, the aquatic carnivore Enhydriodon (an otter) has the lowest $\delta^{18} \mathrm{O}$ of all species. Conversely, the ursid Agriotherium (a bear) has the highest carnivore $\delta^{18} \mathrm{O}$, consistent with anatomical evidence for an omnivorous diet (35). Among herbivores, giraffids (Giraffa and Sivatherium) have the highest $\delta^{18} \mathrm{O}$ and lowest $\delta^{13} \mathrm{C}$ values, whereas grazing equids (Eurygnathohippus), alcelaphines, bovines, hippotragines, and rhinocerotids show the converse. Among primates, Kuseracolobus has higher $\delta^{18} \mathrm{O}$ and lower $\delta^{13} \mathrm{C}$ than Pliopapio, which resembles the difference between modern folivorous Colobini and more omnivorous Papionini $(36,37)$.

The carbon isotopic composition of four of five Ardipithecus ramidus individuals is close to
Fig. 3. Mesowear analysis results for the second molar paracone apex of fossil ungulates. Cusp shape was scored qualitatively as sharp, rounded, or blunt. The relative difference in height between tooth cusp apices and intercusp valleys (occlusal relief) was qualitatively scored as either high or low (large or small distance between cusp apex and intercusp valley, respectively). Histograms show the results on the mesowear variables measured (i.e., the percentages of sharp versus rounded versus blunt cusp shapes and the percentages of high versus low occlusal relief).

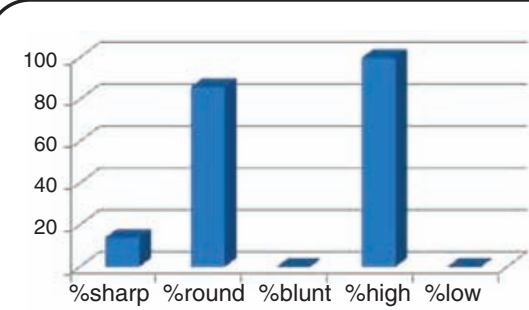

Aepyceros

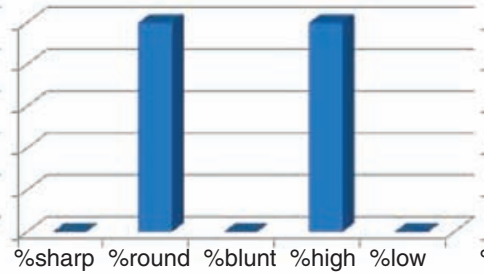

Alcelaphini

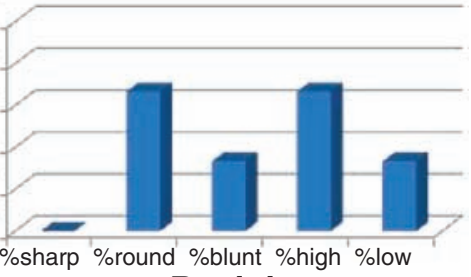

Bovini

\section{Mesowear Results}
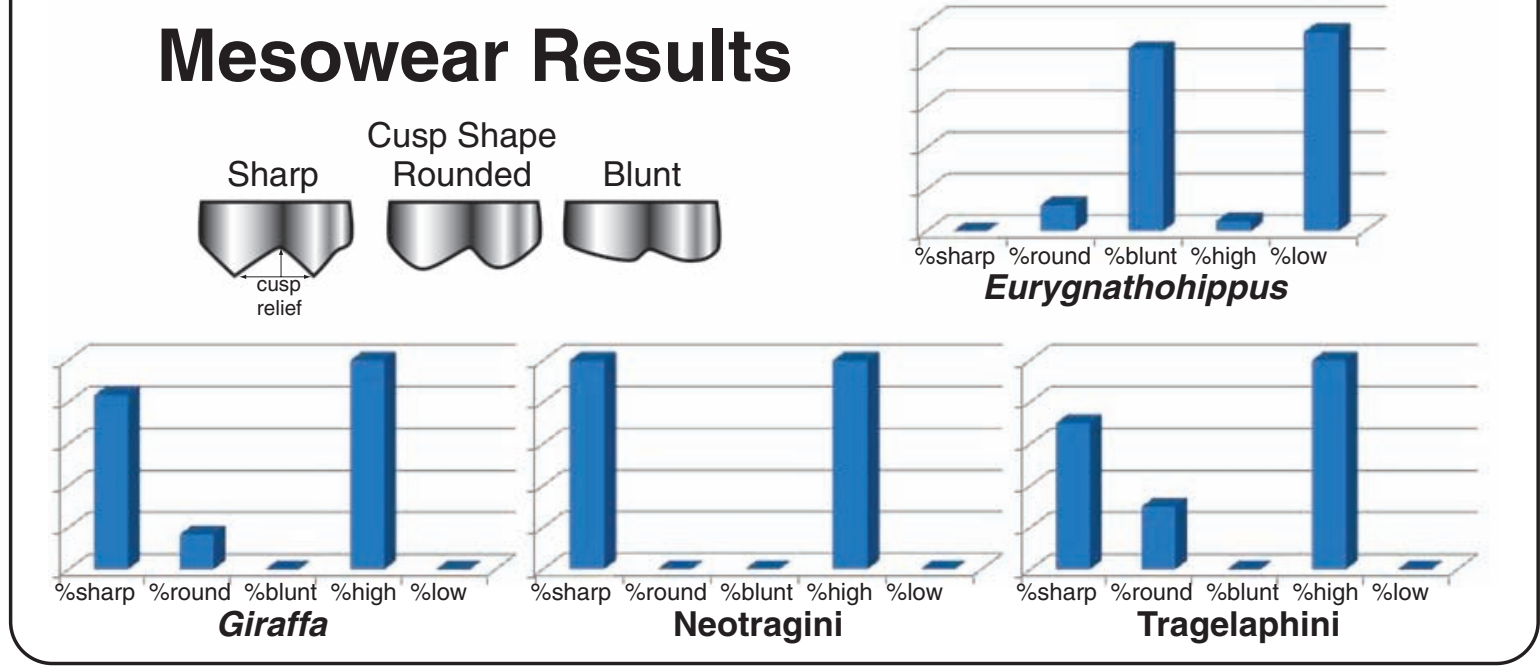
that of Pliopapio, reflecting diets that included small amounts of ${ }^{13} \mathrm{C}$-enriched plants and/or animals that fed on such plants. Ardipithecus consumed slightly more of these resources than modern savanna woodland chimpanzees (38) but substantially less than later Plio-Pleistocene hominids $(39,40)$. The fifth individual has a $\delta^{13} \mathrm{C}$ value of -8.5 per mil (\%o), which is closer to, though still lower than, the means for Australopithecus africanus, Au. robustus, and early Homo $(39,40)$. Slightly lower $\delta^{18} \mathrm{O}$ compared with Pliopapio and Kuseracolobus suggests that Ardipithecus obtained more water from fruits, bulbs, tubers, animals, and/or surface sources.

The isotopic composition of the Aramis mammals between the two tuffs (Fig. 4 and table S4) conforms broadly to patterns expected for their modern congeners across the forest-woodlandsavanna spectrum $(37,38)$ in the East African rift and is consistent with other early Pliocene assemblages $(39,40)$. Relatively low primate, giraffid, tragelaphine, and Deinotherium $\delta^{13} \mathrm{C}$ values indicate that small patches of closed canopy forests were present, although woodlands to wooded grasslands probably dominated. Low $\delta^{13} \mathrm{C}$ values for hyaenids suggest that browsing prey contributed more to their diet compared to their modern congeners in grazer-dominated open savanna environments (37). This is congruent with the numerical dominance of browsing tragelaphines and accords with other evidence for the dominance of woodlands in the $4.4 \mathrm{Ma}$ local environment occupied by Ardipithecus (2,3). A small number of rare grazing species - mainly equids, alcelaphines, hippotragines, and some impala, rhino, and bovines - have high $\delta^{13} \mathrm{C}$ and $\delta^{18} \mathrm{O}$, indicating that they fed on waterstressed $\mathrm{C}_{4}$ plants in drier, open environments (41). These taxa comprise a small portion of the overall assemblage.

The large range of $\delta^{18} \mathrm{O}$, particularly the large difference $(9.6 \%$ ) between water-independent (evaporation-sensitive) Giraffidae (Giraffa and Sivatherium) and water-dependent (evaporationinsensitive) Hippopotamidae, suggests a mean annual evaporative water deficit of $\sim 1500 \mathrm{~mm}$ (41). Therefore, Aramis was a generally dry woodland setting far from riparian environments. Enamel isotopes of these taxa from nearby penecontemporary sites at Gona (42) (SOM text S3 and fig. S2) have a $\delta^{18} \mathrm{O}$ difference of only $4.6 \%$, reflecting an annual water deficit of $\sim 500 \mathrm{~mm}$

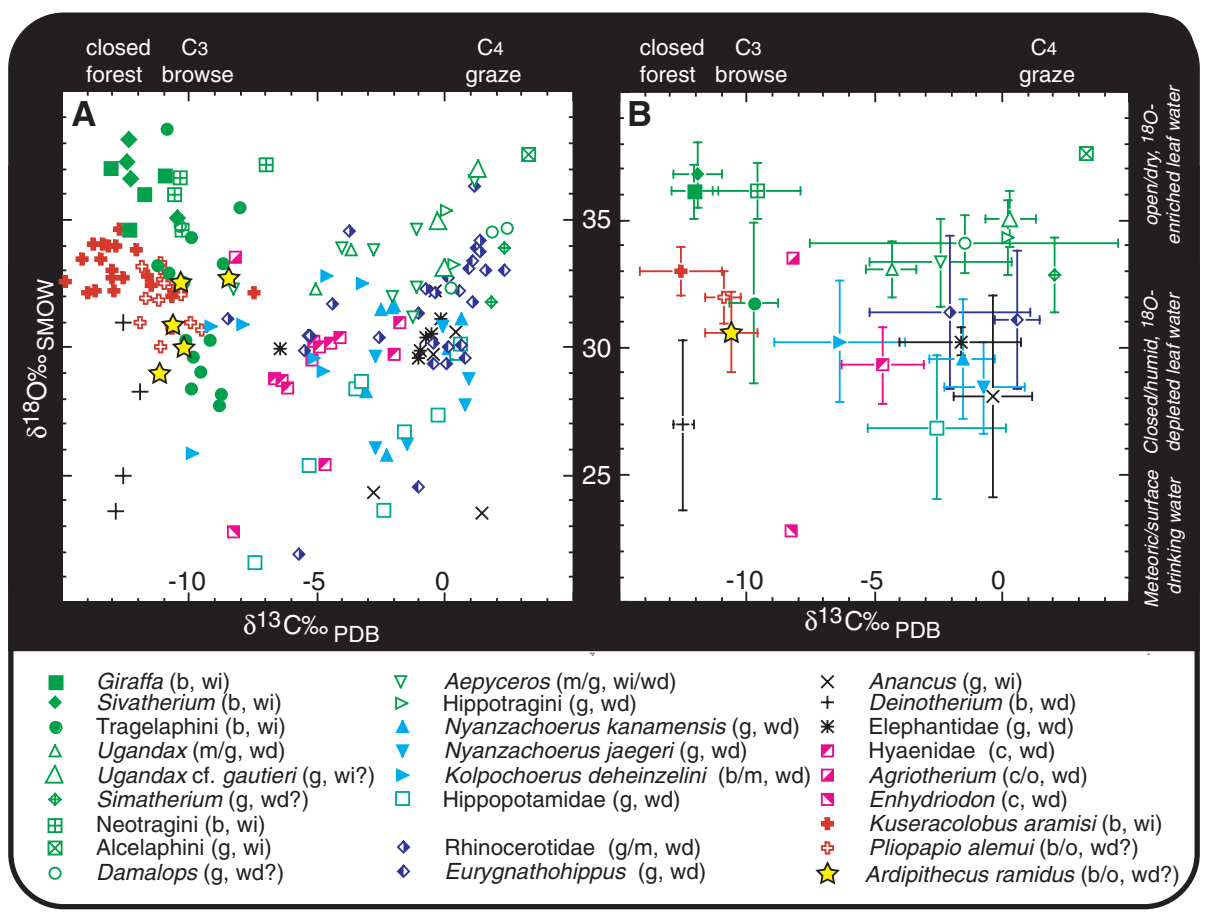

Fig. 4. Carbon and oxygen isotopic composition of mammal tooth enamel from the Lower Aramis Member of the Sagantole Formation in the Middle Awash Valley. (A) Individual $\delta^{13} \mathrm{C}$ and $\delta^{18} \mathrm{O}$ values plotted by taxon. (B) Bivariate means \pm 1 SD. See SOM text S3 for methods and interpretations, table S3 for raw data and statistics, and fig. S1 for comparison with species also occurring in roughly contemporaneous deposits at Gona (42). Food and drinking habits are inferred from closest living relatives and from carbon and oxygen isotope ratios. b, browser $\left(C_{3}\right.$ feeder); $m$, mixed grazer/browser $\left(C_{3}\right.$ and $C_{4}$ feeder); g, grazer (mainly $C_{4}$ grasses); wi, water-independent (evaporation-sensitive) (41) or obtaining substantial amounts of water from green leaves; wd, water-dependent (evaporation-insensitive) (41), relying on drinking water when plant leaves are dry; c, carnivore; o, omnivore, including diets with leaves fruit, tubers, roots, flowers (all predominantly $C_{3}$ ), seeds, fungi, and vertebrate and invertebrate animal matter. Diets, water use, and habitat preferences of species of extinct genera and families are indicated in italics because they are more intrinsically uncertain. Interpretations are described and justified in detail in SOM text S3.
(41). Consistently lower oxygen isotope ratios support geological evidence that Gona was close to permanent water (43), but higher carbon isotope ratios for all Gona browsers are inconsistent with greater water availability (SOM text S3).

Other ecological approaches. An approach to deducing ancient environment is to first assign each mammal taxon in a fossil assemblage to an ecological category (usually based on diet and locomotion) and then compare the proportions of these categories in the fossil sample to a range of similarly categorized extant communities $(44,45)$. This approach uses only the presence or absence of taxa, so it is subject to taxonomic and taphonomic biases involving small samples and mixing. Furthermore, the results are often of low resolution because biased local fossil assemblages are compared to variably recorded modern communities that pool multiple habitats (21). Ardipithecus ramidus was previously interpreted as inhabiting a woodland or dry forest based on a preliminary Aramis faunal list (about $10 \%$ of the sample now available) (40). Although the full faunal list produces results consistent with this finding, these results are not highly robust because the data broadly overlap among distinct environments (e.g., open, riparian, medium-density, and closed woodland) (47).

Other measures of abundance also provide information on the trophic structure of mammalian community represented by the Ardipithecusbearing Lower Aramis Member. Although there are many grazing and carnivorous species (Fig. 5), these taxa are rare (48), so a strict presence/ absence evaluation distorts the ecological signal. When measures of relative abundance (NISP and $\mathrm{MNI}$ ) are included, along with direct information on trophic levels from the stable isotope and mesowear results, a different picture emerges.

These combined data show that the large mammal biomass at Aramis was dominated by browsers and frugivores (including frugivorous animals that consume leaves as a substantial part of their diet). It is unlikely that a plethora of mammals dependent on browse and fruit would have been able to subsist in an environment without abundant trees, the presence of which is witnessed by fossil pollen as well as abundant seeds, wood, phytoliths, and rhizoliths (2).

Hominid habitat. Establishing habitat (as opposed to general environment) is crucial for illuminating the paleobiology of any fossil species, including hominids. On the basis of mixed fossil faunas, it has been previously proposed that "early hominids were apparently not restricted to a narrow range of habitats." [(8), p. 571]. However, this raises the question of whether the hominids actually occupied a wide range of habitats or whether taphonomic processes and sampling biases have mixed hominid remains with those of species from biotopes that hominids rarely, if ever, frequented. Many fossil assemblages simply do not preserve the necessary temporal and spatial resolution needed to determine whether hominids preferred the riverine forest, lake margin, 


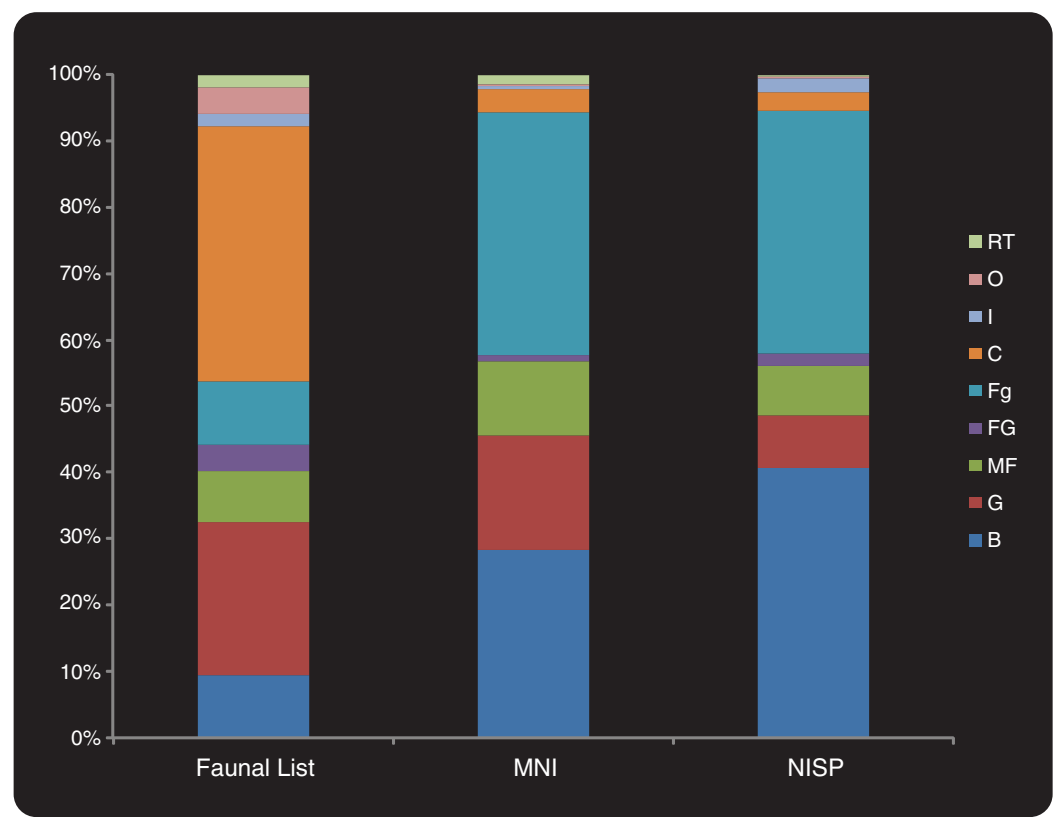

Fig. 5. Trophic ecovariable distributions by faunal list, dental NISP, and dental MNI. Comparisons of the Aramis trophic structure based on the faunal list versus specimen-level, dental relative abundance data as measured by NISP and MNI. Grazing and carnivorous species are abundant in the faunal listbased trophic structure, whereas browsers and frugivores dominate when NISP and MNI data are incorporated. B, browser; G, grazer; MF, mixed feeder; FG, fresh grass grazer; Fg, Frugivore (includes fruit and leaves); C, carnivorous; I, insectivorous; 0 , omnivorous; RT, root and tuber.

bushland, savanna, and/or woodland habitats demonstrably available within a few kilometers of most depositional loci within rift valley settings.

For example, Ardipithecus ramidus has also been found at Gona, about $70 \mathrm{~km}$ to the north of Aramis, in a valley margin environment where lake deposits interfingered with small fluvial channels or lapped onto basaltic cones and flows (43). At Gona, the dominance of $\mathrm{C}_{3}$ plants indicated by paleosol isotopes contrasts with the $\mathrm{C}_{4}$ plant signal in many associated ungulate grazers (indicated by enamel isotopic data). Levin et al. thus concluded that Ardipithecus "...may have inhabited a variety of landscapes and was not as ecologically restricted as previous studies suggest" [(42), p. 232]. The Gona paleontological and isotopic data show only that a range of habitats was present, and the attribution of Ardipithecus to any particular set of the available biotopes is problematical in this mixed assemblage (49). Fish, birds, browsers, horses, and hominids are all frequently found in a single mixed fossil assemblage in a fluviatile or near-shore deposit. This does not mean that the fish were arboreal or that horses were aquatic. Neither do such data mean that the hominids exploited all potentially available habitats.

The Lower Aramis Member deposits provide fossil samples that evidence a range of environments in the region at $4.4 \mathrm{Ma}(2,3)$. However, the consistent association of $A r$ ramidus with a particular fauna and flora in deposits between SAG-VP-7 and KUS-VP-2 suggests its persistent occupation of a woodland with patches of forest across the paleolandscape $(2,3)$. Ardipithecus has not been found in the apparently more open settings to the southeast. There is no evidence of any taphonomic bias related to Ardipithecus that might produce this pattern (3) and no evidence of any other spatial or stratigraphic clustering within the 4.4 Ma Lower Aramis Member interval.

Based on a range of independent methods for inferring habitat-based large samples of consilient spatial, geological, and biological evidence generated from diverse sources, we therefore conclude that at Aramis, Ar. ramidus resided and usually died in a wooded biotope that included closed through grassy woodlands and patches of true forest [sensu (6)]. There is no evidence to associate this hominid with more open wooded grasslands or grassland savanna.

Isotopic data indicate that the Ar. ramidus diet was predominantly forest- to woodland-based. This interpretation is consistent with evidence of the dental and skeletal biology of this primate (1). The ecological context of 4.4 Ma Aramis hominids, combined with their absence or extreme rarity at Late Miocene and Early Pliocene sites, suggest that the anatomy and behavior of the earliest hominids did not evolve in response to open savanna or mosaic settings. Rather, this clade appears to have originated within more closed habitats favored by these peculiar primates until the origin of Australopithecus, and perhaps even beyond (50).

1. T. D. White et al., Science 326, 64 (2009).

2. G. WoldeGabriel et al., Science 326, 65 (2009).

3. A. Louchart et al., Science 326, 66 (2009).

\section{References and Notes}

4. This assemblage is the one co-occurring with Ardipithecus and excludes the small contemporary samples of fossils from the more easterly localities of SAG-VP-1 and -3; see $(2,3)$ and table S1 for details.

5. Included in the larger mammal subassemblage analyzed here are the following taxa: Artiodactyla, Perissodactyla, Proboscidea, Primates, Carnivora (except Viverridae), and Tubulidentata.

6. F. White, The Vegetation of Africa, Natural Resources Research, Vol. 20. (United Nations Scientific and Cultural Organization, Paris, 1983).

7. T. White, in Evolutionary History of the Robust Australopithecines, F. Grine, Ed. (Aldine de Gruyter, New York, 1988), pp. 449-483.

8. M. G. Leakey, C. S. Feibel, I. McDougall, A. Walker, Nature 376, 565 (1995)

9. G. WoldeGabriel et al., Nature 371, 330 (1994).

10. N. E. Sikes, B. A. Wood, Evol. Anthropol. 4, 155 (1995).

11. B. R. Benefit, in African Biogeography, Climate Change, and Human Evolution, T. Bromage, F. Schrenk, Eds. (Oxford Univ. Press, New York, 1999), pp. 172-188.

12. M. G. Leakey, in African Biogeography, Climate Change, and Human Evolution, T. Bromage, F. Schrenk, Eds. (Oxford Univ. Press, New York, 1999), pp. 271-275.

13. Taphonomic and curatorial biases inevitably compromise quantitative interpretations of any assemblage, including Aramis. For example, a single hominid canine may break into only a few identifiable fragments, whereas one elephantid's tusk or molar can shatter into thousands of identifiable fragments. Simple comparisons of fragment abundance can therefore be misleading. Our abundance data take these potential problems into account (see Fig. 1 for details).

14. S. R. Frost, Am. Mus. Novit. 3350, 1 (2001).

15. J. F. Oates, A. G. Davies, E. Delson, in Colobine Monkeys: Their Ecology, Behaviour, and Evolution, A. G. Davies, ]. F. Oates, Eds. (Cambridge Univ. Press, Cambridge, 1994) pp. 45-74.

16. P. Shipman, ]. Harris, in Evolutionary History of the Robust Australopithecines, F. Grine, Ed. (Aldine de Gruyter, New York, 1988), pp. 343-381.

17. E. S. Vrba, in Fossils in the Making, A. Behrensmeyer, A. P. Hill, Eds. (Univ. of Chicago Press, Chicago, 1980), pp. 247-271.

18. R. Bobe, G. G. Eck, Paleobiology 27, 1 (2001).

19. G. Suwa et al., J. Vert. Paleontol. 23, 901 (2003).

20. The Aramis Tragelaphus of. moroitu has a body size close to that of the living nyala ( $T$. angasii) and is likely a direct descendent of the $T$. moroitu recorded from the Mio-Pliocene of Asa Koma and Kuseralee.

21. D. Su, thesis, New York University (2005).

22. R. Bobe, J. Arid Environ. 66, 564 (2006).

23. K. E. Reed, J. Hum. Evol. 54, 743 (2008).

24. H. A. Hespenheide, Annu. Rev. Ecol. Syst. 4, 213 (1973).

25. D. DeGusta, E. S. Vrba, J. Archaeol. Sci. 30, 1009 (2003).

26. D. DeGusta, E. S. Vrba, J. Archaeol. Sci. 32, 1099 (2005)

27. Y. Haile-Selassie et al., Geobios 37, 536 (2004).

28. L. ]. Hlusko, Y. Haile-Selassie, D. DeGusta, Kirtlandia 56, 163 (2007)

29. J. G. Fleagle, Yearb. Phys. Anthropol. 20, 440 (1976).

30. H. B. Krentz, in Theropithecus, N. Jablonski, Ed. (Cambridge Univ. Press, Cambridge, 1993) pp. 383-422.

31. S. Elton, Folia Primatol. (Basel) 73, 252 (2002).

32. M. Fortelius, N. Solounias, Am. Mus. Novit. 3301 1 (2000).

33. Crushing and shearing areas of 10 cercopithecoid molars yielded surfaces that could be included in this analysis. Surface images were made using an SEM at $\times 500$ magnification, and microwear features were collected using the "Microwear" software (v. 2.2, 1996). Microwear features included relatively few pits, with narrow pits and scratches. The microwear on the molars of the Aramis monkeys is consistent with both frugivory and folivory, but they were not routinely feeding on hard objects. A diet of soft, but perhaps tough, foods would be typical of colobines, and the same might be true for the papionin, which has tall molars with a large amount of 
relief and has a low level of basal flare in comparison with other papionins.

34. T. E. Cerling, ]. M. Harris, Oecologia 120, 347 (1999).

35. B. Sorkin, Hist. Biol. 18, 1 (2006).

36. M. L. Carter, thesis, University of Chicago (2001).

37. S. H. Ambrose, M. J. DeNiro, Oecologia 69, 395 (1986).

38. M. Sponheimer et al., J. Hum. Evol. 51, 128 (2006).

39. M. Sponheimer, J. A. Lee-Thorp, in Handbook of Paleoanthropology, W. Henke, I. Tattersall, Eds. (Springer, Berlin, 2007) pp. 555-585.

40. N. J. Van Der Merwe, F. T. Masao, M. K. Bamford, S. Afr. J. Sci. 104, 153 (2008)

41. N. E. Levin, T. E. Cerling, B. H. Passey, ]. M. Harris, J. R. Ehleringer, Proc. Natl. Acad. Sci. U.S.A. 103, 11201 (2006).

42. N. E. Levin, S. W. Simpson, ]. Quade, T. E. Cerling, S. R. Frost, in The Geology of Early Humans in the Horn of Africa, ]. Quade, ]. Wynn, Eds. (Geological Society of America Special Papers, 2008), vol. 446, pp. 215-234.

43. J. Quade et al., in The Geology of Early Humans in the Horn of Africa, ]. Quade, J. Wynn, Eds. (Geological Society of America Special Papers, 2008), vol. 446, pp. 1-31.
44. P. J. Andrews, J. M. Lord, E. M. Nesbit Evans, Biol. J. Linn. Soc. Lond. 11, 177 (1979)

45. K. Kovarovic, P. Andrews, L. Aiello, J. Hum. Evol. 43, 395 (2002).

46. P. Andrews, L. Humphrey, in African Biogeography, Climate Change, and Human Evolution, T. Bromage, F. Schrenk, Eds. (Oxford Univ. Press, New York, 1999), pp. 282-300.

47. Our analysis also raised numerous questions about the assumptions and procedures underlying such efforts.

48. For example, there are 12 "grazing" taxa compared to only 5 "browsing" taxa, but the former are represented by only 152 specimens, whereas the latter are represented by 758 (NISP).

49. It is evident that in most rift-valley depositional settings, a variety of environments would almost always have been available to hominids. Of primary interest is determining whether any one of these environments was the preferred habitat of these primates. Mixed assemblages cannot usually do this.

50. T. D. White et al., Nature 440, 883 (2006)

51. Supported by NSF (grants SBR-82-10897, 93-18698, 9512534, 96-32389, 99-10344, and 03-21893 HOMINID-
RHOI; and grant SBR 98-71480 for mass spectrometry instrumentation at the Environmental Isotope

Paleobiogeochemistry Laboratory) and the Japan Society for the Promotion of Science (G.S. and H.S.). We thank L. Bach, H. Gilbert, and K. Brudvik for illustrations; the Ministry of Tourism and Culture, the Authority for Research and Conservation of the Cultural Heritage, and the National Museum of Ethiopia for permissions and facilitation; and the Afar Regional Government, the Afar people of the Middle Awash, and many other field workers for contributing directly to the data.

\section{Supporting Online Material}

www.sciencemag.org/cgi/content/ful//326/5949/67/DC1

SOM Text

Figs. S1 and S2

Tables S1 to S5

References

4 May 2009; accepted 14 August 2009

$10.1126 /$ science. 1175822 